\title{
Viajar também é escrever
}

\author{
Traveling is also writing \\ Claudete DAFLON \\ Universidade Federal Fluminense (UFF)
}

RESUMO: Propõe-se uma reflexão sobre as relações entre viajar e escrever de modo a superar uma abordagem subordinada às definições do gênero do relato de viagem. Entende-se, primeiramente, que são relevantes e profícuas as formas como escrita e viagem se relacionam no contexto dos processos de formação e produção intelectual. A partir dessa premissa, considera-se que a maneira como o deslocamento se inscreve no texto se caracteriza pela diversidade e revela a importância de experiências de trânsito na criação literária. Assim, sem se ater a uma discussão sobre a especificidade da escrita decorrente de viagem, deseja-se explorar as implicações dos diferentes modos de viajar em estreita consonância com formas de escrever, especialmente aquelas de natureza literária.

PALAVRAS-CHAVE: Viagem. Escrita. Ficção.

ABSTRACT: We propose a reflection about the relationship between voyage and writing for overcome a approach dependent on the definitions of travel literature as genre. We understand, in first place, that the ways as writing and voyage relate each other are relevant and productive in intellectual upbringing and production processes. From this point of view, we take into account the way how the displacement inscribes itself in text is characterized by the diversity and it reveals the importance of dislocation's experiences in literary creation. So we aim explore the implications of the different ways of travelling without worry about a discussion on the specificity of the writing that results from the travel. We intend to discuss this subject in consonance to ways of writing, specially those of literary nature.

KEYWORDS: Voyage. Writing. Fiction. 


\section{Introdução}

Em certo sentido, a popularidade do relato de viagem enquanto gênero representou também seu esgotamento, de modo que intelectuais e escritores, no século XX, viam com desconfiança a prática desse tipo de narrativa. No entanto, isso não significou o abandono da escrita decorrente de experiências de deslocamento. Afinal, o que dizer de Claude Lévi-Strauss, quando inicia Tristes Trópicos afirmando: "Odeio as viagens e os exploradores. E eis que me preparo para contar minhas expedições" (LÉVISTRAUSS, 1996, p.15)? O impacto da afirmativa se deve, em grande parte, ao fato de se estar diante de um livro de viagens. Por outro lado, a condição de viajante bem como o registro escrito são apresentados como decorrência inevitável do ofício de etnógrafo.

Se parece claro que viajar e escrever são processos associados, de modo que o deslocamento muitas vezes leva a práticas de escrita, dificilmente se pode restringir essa relação à realização de relatos comprometidos com uma atitude inventariante, ainda que uma tradição de relatos aponte nessa direção. Na verdade, as formas como a produção textual se realiza a partir da experiência do trânsito são múltiplas e assinalam o papel relevante que a viagem pode assumir no processo de criação literária. Nesse sentido, merecem atenção os modos como viajar e escrever se alimentam reciprocamente.

Diante disso, propõe-se discutir aspectos envolvidos na condição conjunta de escritor-viajante. Para tanto, faz-se necessário considerar como se compreende o deslocamento, uma vez que a ideia de viagem deve-se, entre outras coisas, ao seu próprio registro escrito. Em outras palavras, uma maneira de definir a experiência viajante seria a partir da escrita a ela associada. Essa proposta constrói-se pela superação de abordagens do tema fundadas nas prerrogativas do gênero, ou seja, objetiva-se tratar de uma relação que se estabelece também (ou principalmente) pelo ficcional sem se ater a textos reconhecidos como relatos de viagem. Isso significa assumir que são diversas as formas pelas quais o viajar se inscreve na produção textual. 


\section{0 narrador de viagem}

O mercador que viajou por regiões muitas vezes desconhecidas para o mundo ocidental de sua época, mais precisamente pelo "exótico" oriente, chega à sua terra natal com experiências as mais ricas e variadas. Transmiti-las reveste-se da utilidade de expor as maravilhas e possibilidades do mundo àqueles que não saíram de seus lares.

[...] não houve cristão, nem sarraceno, nem pagão, nem tártaro, nem índio, nem homem algum de geração alguma, que tanto tivesse visto, investigado e sabido das maravilhas e diversidades do mundo como o mencionado Marco Polo viu, investigou e soube; [...] por isso vos digo que seria grande desventura não ficarem escritas todas as preciosas maravilhas que viu e ouviu, para que todos os povos que não as viram nem conheceram delas tomem conhecimento através deste livro. (POLO, 1999, p.46)

Portanto, Marco Polo, como a citação retirada de $O$ livro das maravilhas, publicado também como As viagens de Marco Polo, já elucida, não só tem experiência a transmitir, mas também possui o objetivo prático que caracteriza o narrador tal qual o apresenta Walter Benjamin. De fato, a acepção benjaminiana de narrador não se confunde com o emprego usual do termo. $\mathrm{O}$ pensador alemão reconhece como narrativas, especificamente, as histórias pertencentes ao universo da oralidade e do coletivo, dentro do qual é possível intercambiar experiências. Narrar seria, portanto, uma arte relacionada, a um só tempo, à sabedoria do narrador e ao trabalho do artífice, uma vez que a oficina do artesão constituiria o espaço ideal para se contarem histórias, continuadamente repetidas e transmitidas de geração a geração. Nesse espaço, coexistiriam o sedentário, que nunca se aventurou a viajar, mas conhece bem todas as tradições de seu povo, e o viajante que, após sua jornada, volta para casa repleto de histórias que animam a imaginação.

O mestre sedentário e os aprendizes migrantes trabalhavam juntos na mesma oficina; cada mestre tinha sido um aprendiz 
ambulante antes de se fixar em sua pátria ou no estrangeiro. Se os camponeses e os marujos foram os primeiros mestres da arte de narrar, foram os artífices que a aperfeiçoaram. No sistema corporativo associava-se o saber das terras distantes, trazidos para casa pelos migrantes, com o saber do passado, recolhido pelo trabalhador sedentário. (BENJAMIN, 1994, p.199)

Tecer a narrativa se aproxima, assim, do trabalho do artesão. Por outro lado, a sabedoria, adquirida via experiência apreensível no remoto temporal ou espacial, conferia autoridade ao narrador. $\mathrm{Na}$ base da narrativa está o saber oriundo da experiência, logo, a sabedoria exígua compromete o narrador: "A arte de narrar está definhando porque a sabedoria - o lado épico da verdade - está em extinção" (BENJAMIN, 1994, p.200-201).

A narrativa, por esse ponto de vista, não encontraria mais espaço no mundo do romance e da informação. Um mundo em que a experiência, tal como a entende Walter Benjamin, torna-se uma impossibilidade:

No final da guerra, observou-se que os combatentes voltavam mudos do campo de batalha não mais ricos, e sim mais pobres em experiência comunicável. E o que se difundiu dez anos depois, na enxurrada de livros sobre guerra, nada tinha em comum com uma experiência transmitida de boca em boca. Nada havia de anormal nisso. Porque nunca houve experiências mais radicalmente desmoralizadas que a experiência estratégica pela guerra de trincheiras, a experiência econômica pela inflação, a experiência do corpo pela guerra de material e a experiência ética pelos governantes. (1994, p.198)

Subtrai-se, desse modo, o comunicável que se processa oralmente (de boca em boca), uma vez que, num contexto de incomunicabilidade e isolamento, cessa o intercâmbio coletivo de experiências. Isolar-se é, antes de tudo, não ouvir e, portanto, não compartilhar. Não se volta mais para o outro a fim de dar ou receber conselhos. Por conseguinte, a dissociação com a tradição 
oral assim como a solidão do indivíduo caracterizam o romance e marcam a profunda distinção entre este e a narrativa tomada como modelo. Entretanto, ainda segundo Benjamin (1994, p. 203), é a informação que dá o golpe certeiro na arte de narrar:

Cada manhã recebemos notícias de todo o mundo. E, no entanto, somos pobres em histórias surpreendentes. A razão é que os fatos já nos chegam acompanhados de explicações. Em outras palavras: quase nada do que acontece está a serviço da narrativa, e quase tudo está a serviço da informação. Metade da arte narrativa está em evitar explicações.[...] O extraordinário e o miraculoso são narrados com a maior exatidão, mas o contexto psicológico da ação não é imposto ao leitor. Ele é livre para interpretar a história como quiser, e com isso o episódio narrado atinge uma amplitude que não existe na informação.

A narrativa não explica nada, por isso perdura a sua capacidade de gerar espanto. A informação, por sua vez, esgotase. Há na informação a cisão entre real e imaginário, que torna este último indesejável uma vez que se pretende relato fidedigno de uma determinada realidade: daí a necessidade de que tudo seja devidamente explicado. Tanto assim que a informação exige a verificação, que nada mais é que a comprovação desse compromisso com o real. Embora o relato do viajante Marco Polo se apresente, a princípio, como fiel à realidade, compromissado com o inventário e a descrição das terras e povos orientais desconhecidos pelos europeus, As viagens de Marco Polo constituem uma narrativa na acepção benjaminiana, uma vez que o viajante, ligado a uma tradição oral, ao narrar suas experiências, não se limita a informar: circula entre as fronteiras da realidade e da fantasia, mesmo ao afirmar que tudo relata exatamente como viu ou ouviu. A esse respeito, ao debruçar-se sobre a narrativa do veneziano, comenta Gillermo Giucci (1989, p.17):

Ainda que a descrição das riquezas e costumes asiáticos constitua a maior parte do livro, ela não representa - na perspectiva do leitor europeu - o aspecto primordial do relato. Ou melhor, o que chama especialmente a atenção do leitor 
são as descrições de riquezas e costumes contíguas ao campo do maravilhoso. E se de um relato testemunhal e objetivo passamos a um relato maravilhoso, pois sob este rótulo merece ser agrupada uma série de descrições que incluem da celebração de festejos à representação de cidades e riquezas, isto comprova a facilidade com que o maravilhoso se infiltra na realidade. Não é difícil encontrar a razão desta intrusão, e até da confusão do real com o maravilhoso. Enquanto o viajante seleciona os aspectos dignos de menção e exclui os traços supérfluos, o 'texto' do leitor se constrói por uma expansão da imaginação.

Tal expansão só é possível porque na narrativa não se fornecem explicações e assim se preserva o espaço por onde pode infiltrar-se o imaginário, ainda que o mercador defenda a veracidade do seu relato. Essa defesa se revela ainda nas palavras daquele que foi o escriba responsável pelo registro das aventuras de Marco Polo: Rusticiano de Pisa, a quem o viajante ditou suas histórias.

E apresentaremos as coisas exatamente como foram vistas e tão somente como foram ouvidas, para que nem um pingo de falsidade possa arruinar a verdade de nosso livro, e que todos aqueles que o lerem ou ouvirem possam acreditar integralmente na veracidade de todos os seus conteúdos (POLO, 1956, p.1).

A tentativa de comprovação da fidedignidade do texto, ou seja, do compromisso com o real, se situa dentro de um processo de valorização da própria narrativa. A importância dada ao vínculo com a realidade está indicada na introdução à edição americana de 1956 do livro As viagens de Marco Polo em que Thomas Yoseloff (1956) apresenta o veneziano como um cronista que se atém ao fato, buscando sempre distingui-lo da ficção. A narrativa de viagem do mercador procuraria, desse modo, colocarse como registro fiel de uma realidade observada. No entanto, o próprio Yoseloff (1956) assinala a propriedade que a narrativa de Marco Polo tem de despertar a imaginação e sua sobrevivência 
entre os leitores, apesar de muitas das informações do texto já terem sido superadas (1956). Em outras palavras, ainda que, a princípio, a narrativa se afirme como retrato fiel e seja apreciada quanto a essa fidelidade aos fatos, o que permanece, na verdade, é o fascínio do discurso. Além disso, torna-se evidente que, a despeito do apelo à veracidade como forma de legitimação do texto, este seria mais lido pela sua narrativa sedutora do que pela descrição comprometida com o factual. Ao não dar explicações, a narrativa permite a extensão da imaginação e garante, assim, sua durabilidade. Nessa óptica, os leitores do livro seriam, em outra face, Kublai Khan: ouvinte atento às maravilhas narradas pelo mercador de Veneza.

Por outro lado, não se deve perder de vista que o narrador é antes de tudo alguém capaz de dar conselhos. Narrar a viagem representa, desse modo, compartilhar as experiências vividas por quem viaja com os que, por opção ou não, recusaram-se a viajar. $\mathrm{O}$ viajante precisa contar para permitir aos que ficaram a aquisição de conhecimento, o que dá a esse narrador a dimensão utilitária assinalada por Walter Benjamin (1994, p.200).

Tudo isso esclarece a natureza da verdadeira narrativa. Ela tem sempre em si, às vezes de forma latente, uma dimensão utilitária. Essa utilidade pode consistir seja num ensinamento moral, seja numa sugestão prática, seja num provérbio ou numa norma de vida - de qualquer maneira, o narrador é um homem que sabe dar conselhos.

Marco Polo tem o que contar na medida em que as experiências que traz consigo, ao serem transmitidas, representarão algum tipo de proveito para os que se apresentam como ouvintes: é possível aprender com as palavras desse narrador. Isto só é viável porque a história de Polo está mergulhada na tradição oral. Um aspecto relevante acerca disso é o fato de Marco Polo não ter escrito o livro e sim tê-lo ditado para um companheiro de cela. Este, identificado como Rusticiano de Pisa, é o autor do prólogo de As viagens de Marco Polo. O livro, dessa forma, é apresentado por aquele que registrou na escrita o relato oral do viajante. A 
prisão, entendida como a espera da morte, configura-se como momento apropriado para a transmissão de experiência. Marco Polo transmite suas experiências apenas oralmente, primeiro a Kublai Khan depois ao companheiro de cela, neste último caso para que tudo seja registrado pela escrita. De qualquer maneira, é sempre oralmente que se processa essa comunicação. Não é por acaso que, na conclusão do livro, o narrador assinala: "Ouvistes todos os feitos dos tártaros e dos sarracenos, dos seus costumes e dos de outros países do mundo, tudo quanto deles se pode dizer e saber" (POLO, 1999, p.380 - é sintomático o emprego do verbo ouvir na referência ao leitor. $\mathrm{O}$ texto tem suas raízes fincadas na tradição oral.

Remetendo, mais uma vez, à semelhança entre o leitor do livro e Kublai Khan, é possível identificar uma estrutura de relato dentro do relato, uma vez que o narrador do texto escrito apresenta Marco Polo como narrador que se dirige a um ouvinte que o reconhece como tal: o imperador. O leitor-ouvinte assim lê-ouve o relato de Polo que se destina ao imperador mongol; este, o ouvinte primeiro, se confunde com o leitor transmutado também em ouvinte. De qualquer modo, o relato se apresenta como transmissão de experiência a leitores e/ou ouvintes atentos.

Italo Calvino, já em pleno século $\mathrm{XX}$, bem distante dos anos de 1200 em que viveu o mercador veneziano, retoma a figura de Marco Polo para estruturar um novo relato de viagens, que se constrói em um momento em que não há mais a possibilidade do narrador clássico ${ }^{1}$ pertencente a uma tradição oral que processa o intercâmbio de experiências. Assim, em sua relação metalinguística, ou mesmo de metarrelato, o diálogo entre

\footnotetext{
${ }^{1}$ Adotar-se-á aqui a denominação "narrador clássico” em referência ao narrador benjaminiano. Tal opção se inspirou na proposta de Silviano Santiago (1989) apresentada em seu texto "O narrador pós-moderno", de 1986, publicado no livro $\mathrm{Na}$ malha das letras, segundo a qual o narrador da tradição oral seria o narrador clássico. A vantagem de utilizar-se essa terminologia está em evitar possíveis confusões decorrentes do emprego de termos como narrador e narrativa em sentido mais geral, ou seja, distinto da acepção formulada por Walter Benjamin.
} 
o narrador e seu ouvinte, no caso, respectivamente, Marco Polo e Kublai Khan, constrói a narrativa pelo sistema de combinações em que se opera o imaginário. $\mathrm{O}$ relato de viagem deixa de ser então apenas um processo de transmissão de experiências para ser também a construção destas por meio da interação entre narrador e ouvinte. A viagem se confunde, então, com o próprio discurso.

Kublai Khan percebera que as cidades de Marco Polo eram todas parecidas, como se a passagem de uma para a outra não envolvesse uma viagem mas uma mera troca de elementos. Agora, para cada cidade que Marco lhe descrevia, a mente do grande Khan partia por conta própria, e, desmontando a cidade pedaço por pedaço, ele a reconstruía de outra maneira, substituindo ingredientes, deslocando-os, invertendo-os. (CALVINO, 1994, p.43)

Operando pelo imaginário, o ouvinte/leitor evidencia o processo de composição que revela a natureza dessa escrita feita de deslocamentos. A apresentação em rede de conexões dos trajetos de Marco Polo equivale à estrutura do texto, como bem observa Renato Cordeiro Gomes:

Estas cidades implicam uma cartografia imaginária, sobrepondo os tempos e os espaços num labirinto em que se busca não um ponto de chegada, mas uma infinidade de percursos, uma atividade de conexões - sinaliza Philippe Daros. Cartografia - rede-texto, cuja leitura procura engendrar uma possível legibilidade; leitura que é travessia, passagem: percurso, conexões. Nesta operação, em que tudo se movimenta, num jogo infinitamente aberto e sem solução, somos guiados por Marco Polo, o fabulador proliferante (a imagem da chama), que viaja no império da linguagem. (GOMES, 1994, p.41)

A viagem-discurso de Marco Polo situa este como outro em relação ao Marco Polo seu paradigma. O veneziano de As viagens de Marco Polo funciona como matriz para o viajante do livro de Calvino; no entanto, o paralelo entre um e outro decorre de um movimento duplo de aproximação e distanciamento. Portanto, 
o Marco Polo de As cidades invisíveis, embora seja o mercador viajante, diferencia-se de seu modelo; por isso, continua a ser Polo, mas já é um outro. Uma pergunta se impõe, diante disso: afinal, por que retomar, num romance contemporâneo, a moldura de uma narrativa clássica? E mais: por que a figura do narrador-viajante? Ulla Musarra (1990), ao discutir as relações entre as convenções do romance e a multiplicação das instâncias narrativas, constata que, em muitos textos pós-modernos, são exploradas convenções da tradição romanesca. Ou seja, a multiplicação das instâncias narrativas representa um recurso importante na produção literária contemporânea, uma vez que oblitera as fronteiras entre frame e história narrada e entre a história e 'a história dentro da história' (MUSSARA, 1990, p.216). Se, em As viagens de Marco Polo, há uma preocupação em legitimar como autêntica, verídica, a narrativa; em As cidades invisíveis, os famosos personagens Marco Polo e Kublai Khan são retirados dessa conexão com o real, para que se possam construir as cidades invisíveis. $\mathrm{O}$ narrado como real e como ficcional não são dispostos em uma dicotomia, mas apresentados em uma relação complexa. Não existe a pretensão de dizer onde começa a realidade e termina a fantasia.

Viajar, portanto, no passado, na tradição, é transformálo, salvando-o do esquecimento, tornando-o produtivo: ramos viçosos. Em As cidades invisíveis, este procedimento equivale a viajar pelo território da literatura, por itinerários já esgotados, em que todas as histórias foram contadas até o limite da saturação e só é possível inventariar e revisitar (parece pairar por aí o espírito de Borges). Tais itinerários, portanto, são inscritos numa perspectiva intertextual que os legitima e faz de sua leitura uma viagem na literatura: itinerários que se transformam quando os atravessamos, quando estabelecemos as atividades de conexões, de uma cidade escrita a outra cidade escrita. Nada se passa no real, mas em espaços fictícios. (GOMES, 1994, p.45-46)

A viagem deste Marco Polo se assume viagem literária que ocupa espaços ficcionais construídos na dinâmica da leitura. O Grande Khan queria a verdade, no entanto, Marco "Oferece-lhe 
em suas impressões de viagens, 'aparências ilusórias"' (GOMES, 1994, p.48). A memória entra neste jogo; pois, ainda que não se trate de uma narrativa de memórias, o relato do mercador se edifica a partir da reminiscência, como não deixa escapar o atento Kublai Khan: "-...Portanto, na realidade a sua é uma viagem através da memória!” (CALVINO, 1994, p.93).

A construção do discurso pelo viés memorialista põe em questão o valor verídico da recordação. Ulla Musarra (1990) indica, como tendência da narrativa pós-moderna, o resgate do modelo das memórias, mas com sérias implicações nas relações entre real e ficcional, como em $A d a$, de Vladimir Nabokov. As várias versões que se vão construindo se sobrepõem formando uma espécie da palimpsesto (MUSARRA, 1990, p.222). No entanto, em As cidades invisíveis, apesar de a memória ser importante no jogo narrativo, há um aspecto em sua construção que funciona como o fio condutor que se enrosca na reminiscência da viagem: o discurso. Este é, simultaneamente, construtor e construção, caracterizando o recurso metaficcional empreendido por certas narrativas pós-modernas.

Sem dúvida, para Calvino, a literatura consiste num processo de combinação, como deixa entrever a composição do livro, daí As cidades invisíveis serem resultado de uma matemática permutacional operada pelo imaginário. A opção por um modelo narrativo tradicional apresenta relação intrínseca com esse jogo de combinações, afinal as peças já determinadas se apresentam numa situação relacional nova, o que lhes confere um significado outro. As próprias cidades descritas no romance - as suas distribuições em grupos e a forma como são apresentadas revelam a combinação de elementos como método de construção. Todavia, não é aleatória a combinação, como já se disse, um fio discursivo orienta o jogo:

As cidades, como os sonhos, são construídas por desejos e medos, ainda que o fio condutor de seu discurso seja secreto, que as suas regras sejam absurdas, as suas perspectivas enganosas, e que todas as coisas escondam uma outra coisa. (CALVINO, 1994, p.44). 
O movimento permutacional dirigido por um fio condutor leva a questionar-se, então, a literatura como representação para entendê-la como construção que se apresenta como rede inter $\mathrm{e}$ intratextual. $\mathrm{O}$ romance que remete à aventura da viagem se concretiza como aventura da linguagem: "A linguagem é recrutada para a empresa de construir um outro império - o textual, em que tudo está sob o signo da duplicidade que fomenta os relatórios do veneziano" (GOMES, 1994, p.42).

Assim, enquanto aventura da linguagem, a situação narrativa arquetípica é redimensionada no romance de Calvino:

Nesse contexto que assiste ao declínio de uma tradição e de uma memória comunitária - a degradação da 'Experiência'é que Calvino resgata aquele tipo de narrador, na tentativa de reconstruir um universo incerto, a partir de uma tradição esfacelada (GOMES, 1994, p.43).

Logo Marco Polo de As cidades invisíveis é ao mesmo tempo o mercador de As viagens de Marco Polo, enquanto matriz, mas sobre o qual se delineia outro Marco Polo, o que é discurso, tal qual as cidades. Há de notar-se a alteração tipográfica da letra, pelo emprego ou não do itálico, em As cidades invisíveis, demarcando o que é o diálogo entre Polo e Kublai e o que é a descrição das cidades. Nas situações de diálogo, o narrador está em terceira pessoa e configura-se como extradiegético; quando as cidades são apresentadas, é Marco Polo quem narra para Kublai Khan e, indiretamente, ao leitor. Os níveis diegéticos se embaralham, mas não se pode confundir o discurso com o que descreve, bem avisa o Marco Polo de Calvino.

A leitura de O livro das maravilhas e de As cidades invisiveis permite, portanto, a elaboração de uma discussão em que se considerem as possíveis relações que se constroem entre viagem e escrita, seja numa narrativa do século XIII ou do século $\mathrm{XX}$. Decerto, não se pretende desconsiderar as significativas diferenças históricas que atravessam os séculos que separam as duas narrativas e fazem do Marco Polo de Calvino um outro Marco Polo, distinto do viajante veneziano de O Livro das 
maravilhas. Também não se despreza que as configurações de narrador não podem ser entendidas como a polaridade entre um narrador clássico e um pós-moderno, pois tal posição acarretaria, entre outras coisas, desconsiderar a figuração do narrador moderno. Todavia, a despeito das diferenças, destaca-se, nessa leitura atravessada, o entrelaçamento entre viajar e escrever que torna possível a identificação de uma viagem-discurso, seja quando a narrativa apresenta maravilhas e transmite experiências na esmorecida fronteira entre o real e o imaginário, seja quando se assume como empreitada textual, espaço de reflexão e construção. Ao se assumir esse ponto de vista, a preocupação com a determinação de gêneros não tem sentido. Afinal, quando se almeja discutir a inscrição da viagem na escrita, seja ela ficcional ou não, de forma a percebê-las, viagem e escrita, numa relação dialética, o que menos interessa fazer é uma discussão preocupada com o enquadramento de textos no gênero da literatura de viagem.

\section{Os caminhos da ficção: modos de viajar}

O espaço privilegiado ocupado pela viagem na produção escrita revela-se nos mais variados registros, em suas diferentes naturezas: desde o relato de viagem propriamente dito até a viagem ficcionalizada, passando mesmo pela escrita que envolve, por exemplo, a experiência etnográfica. Não é fortuita, afinal, a configuração da viagem enquanto topos, como bem deixa entrever Elvira Souto, na introdução de seu livro Viagens na Literatura:

A viagem é um daqueles motivos maiores - daqueles temas modelo poderíamos dizer - que, depois de namorarem os poetas, seduziram os estudiosos, e os frutos destas relações apaixonadas foram em verdade tão copiosos e até prolixos que o simples crítico pode sentir-se eximido sem culpa de qualquer esforço teórico suplementar. (SOUTO, 1991)

A configuração da viagem como um motivo maior aponta para a sua contundente presença na produção escrita que tem marcado a literatura ocidental. Desse modo, embora não se trate 
de uma questão nova, a ligação entre viajar e escrever assume tamanha relevância que seu estudo ainda é um desafio à reflexão. Todavia, justamente por ser esta uma discussão há muito em pauta, consolidaram-se no senso comum práticas como o uso metafórico da palavra viagem em referências como viajar pelas palavras, ou mesmo da leitura como uma viagem. Contudo, é recomendável evitar-se o clichê a que pode ser reduzida tal ideia. Por outro lado, a preocupação em empreender uma discussão fértil sobre o tema, de forma alguma, representa um ataque ou repúdio à compreensão metaforizada da viagem, antes revela a busca por espaços de debate que não caiam na armadilha do lugar-comum.

$\mathrm{Na}$ introdução a Viagens na Literatura, Elvira Souto (1991) menciona diversos autores que vão, em casos extremos, definir que toda literatura é uma viagem. Conclui, então, a autora que é duvidoso entender que "[...] sempre e em todo o lugar literário devamos, ou possamos, encontrar uma viagem inscrita no coração do texto" (SOUTO, 1991). No entanto, afirma logo a seguir que:

Do que sim temos certeza é de ser este um tema, e um mito, de decisivo impacto cultural, um dos 'lugares comuns' mais intensamente frequentado por todas as tradições, literárias ou outras. E mais estamos seguros de que, querendo, podemos descobrir uma viagem, implícita e latente, em muitas obras que na superfície imediata do texto tratam doutros assuntos e se articulam sobre estruturas de aparência bem diversa [...]. (SOUTO, 1991)

Ainda que a autora negue inicialmente, parece haver de sua parte uma clara tendência a concordar com a ideia de que literatura e viagem se confundem, o que significaria dizer que todo texto literário é ou contém, de alguma forma, uma viagem. Em ensaio intitulado Mapmaking: the Poet as Travel Writer ('Mapeando: o poeta como escritor de viagem'), Beatriz Badikian (1998, p.73), já no primeiro parágrafo, vai ao encontro dessas frequentes e, por vezes, contundentes associações entre escritor e viajante: 
All poets are travelers. Whether literally or metaphorically, we journey through words to discover new worlds. And we journey through the world to create new words. To trace our "own personal" maps we move through the world with words and through words in the world. During these journeys we also become travel writers of sorts. ${ }^{2}$

A posição apresentada por Badikian (1998) corrobora uma possível identificação entre viagem e literatura, também como resultado de uma compreensão metafórica do que seria viajar. Sem dúvida, o uso da metáfora pode ser bastante proveitoso; porém, o que está em pauta aqui não é o entendimento da produção literária como uma viagem, mas a escrita como uma experiência relacionada efetivamente a processos de deslocamento. Uma vez que se viaje e se escreva, entende-se que a inter-relação entre imaginação e viagem permite uma abordagem do texto do viajante pela fronteira fluida entre o real e a fantasia. De fato, a reflexão sobre as complexas relações entre imaginário e realidade na escrita que se origina do trânsito está na base do próprio debate sobre as relações entre viagem e escrita. Tal problemática mais se acentua quando se considera que o texto, compreendido como primeiro itinerário, motiva a realização de um deslocamento real. $\mathrm{O}$ discurso literário seria, ao mesmo tempo, um convite para o percurso imaginário possibilitado pela leitura e uma espécie de mapa que sugere roteiros, que incita o desejo de viajar, agora não pelas letras, mas por estradas e cidades. Após viajar literariamente, viajar-se-ia então de verdade. Todavia, uma vez realizada esta segunda viagem, o viajante muitas vezes empreende outra, novamente pela escrita. Agora não mais dentro de um processo de leitura que integra o seu processo de formação, mas produzindo ele mesmo a escrita da viagem. Relato de viagem, portanto? Não

2 Todos os poetas são viajantes. Seja literária ou metaforicamente, nós viajamos através das palavras para descobrirmos novos mundos. E viajamos através do mundo para criarmos novas palavras. Para traçar nossos próprios mapas 'pessoais', nós nos movemos pelo mundo com palavras e pelas palavras no mundo. Durante estas viagens, nós nos tornamos escritores de viagem de alguma forma. 
necessariamente, quando se pensa em termos de gênero; sim, quando se refere à escrita ficcional, poética, memorialista, em que se inscreve a viagem e que, por conseguinte, de alguma forma relata a viagem realizada.

Ler, viajar e escrever tornam-se, assim, quase sinônimos, ainda que indubitavelmente diferentes. A sinonímia se deveria ao fato de convergirem num movimento de deslocamento: lerviajar; viajar-viajar e viajar-escrever. A diferença, por sua vez, reside fundamentalmente no caráter distinto da viagem que a leitura promove, daquela que efetivamente se realiza e da que se apresenta como a aventura da escrita. Não se pode perder de vista, no entanto, como longe de se situarem perfeitamente separadas umas das outras, essas possíveis viagens estão o tempo todo ligadas entre si. Também seria equivocado apostar na existência de uma perfeita linearidade que permitiria uma sequência definida: primeiro, ler; segundo, viajar; terceiro, escrever. Na verdade, há uma interpenetração de tempos que se traduz em simultaneidade. Afinal, o intelectual não deixa de ler para viajar ou para escrever, nem precisa necessariamente já ter terminado a jornada para iniciar o seu registro. A simultaneidade, a interpenetração e o movimento de mão dupla caracterizam a relação instituída entre formação e produção. É certamente infrutífero tentar identificar o momento em que cessa o processo formativo e se inicia o produtivo, uma vez que o formar-se tende a não cessar. Por conseguinte, é possível concluir que a discussão que leva em conta tanto a viagem quanto a escrita pode trazer à tona, por um lado, a intrínseca relação que se estabelece entre elas; por outro, a sua articulação com a formação e produção letrada.

Decerto, um movimento contínuo e tenso entre o trabalho de criação e o desenvolvimento intelectual pode ser apreendido por meio da escrita articulada aos diferentes modos de viajar. É corrente a compreensão de que a viagem possa ser entendida de mais de uma forma, o que permite a determinação de tipos de viajantes. Um processo de tipificação, por sua vez, supõe a avaliação de diferenças ao mesmo tempo em que busca uma 
caracterização. Na realidade, quando se fala em uma tipologia de viajantes, está-se afirmando a existência de diferentes formas de viajar. Apesar de considerar necessária a referência ao processo de tipificação, não se pretende circunscrever a discussão a um procedimento meramente classificatório, visto que uma abordagem taxionômica não corresponde aos objetivos pretendidos. O que de fato interessa aqui é a identificação de aspectos próprios à experiência do trânsito que possam contribuir para a discussão que ora se propõe. Afinal, é possível ainda considerar o quão artificiais e estéreis podem ser as pretensões de determinar classificações exatas, posto que muitas vezes predomina uma natural interpenetração entre os tipos propostos.

Há, por outro lado, mais de uma possibilidade de tipificação do viajante. Considerar algumas formulações permite discutir os diferentes critérios que orientaram a determinação de tipos, o que significa colocar em pauta os aspectos que envolvem aproximações e distanciamentos entre práticas de viagem. Isso significa dizer que os critérios empregados para estabelecer distinções podem ser mais interessantes do que os modelos construídos. Assumese, portanto, que o entendimento das questões envolvidas no processo de classificação é mais importante que a preocupação de encaixe em tipos predeterminados.

Uma distinção bastante abrangente e comum é a que se faz entre turista e viajante. São recorrentes as tentativas de definir um e outro a fim de diferenciá-los categoricamente. Todavia, tais tentativas têm-se mostrado no mais das vezes hierarquizantes, já que se reserva ao viajante um status superior ao turista - o primeiro, normalmente, é apresentado como legítimo representante da arte de viajar, enquanto o segundo participa da degradação desta mesma arte.

Marielle Risse, em texto intitulado White knee socks versus photojournalist vests: distinguishing between travelers and tourist ('Meias brancas até o joelho versus vestes de fotojornalista: distinguindo viajantes e turistas'), aponta para o caráter fundamentalmente classista da maior parte dos critérios 
usados para fazer a distinção entre esses dois tipos. Daí dizer-se que o viajante conhece línguas, pode estender sua permanência nos lugares a que chega, costuma fazer uma viagem duradoura, além de visitar lugares reais e nãofalsos. De um lado, as diferenças de tempo, relacionadas à duração da viagem e permanência nos lugares, evidenciam a separação entre viajantes e turistas "by respective wealth"3 (RISSE, 1998, p.44), já que a possibilidade de estender o tempo de permanência nos lugares que visita vai depender dos recursos financeiros de quem viaja; de outro, a discriminação entre lugares falsos e reais parece a princípio mera predeterminação, uma vez que os critérios determinantes do que se julga falso ou verdadeiro não estão disponíveis.

A necessidade de diferenciar-se experimentada por aqueles que se acreditam viajantes está relacionada ao desejo de se preservar enquanto elite diante da massificação sofrida pelo turismo. Maxine Feifer (1986, p.2), em sua discussão sobre a viagem turística, observa:

The Shorter Oxford English Dictionary defines the tourist as "one who travels for pleasure ou culture, visiting a number of places". More and more people are tourists. Tourism is one of the biggest growth industries in the modern industrial world and has enjoyed that status for over twenty years. Yet nobody wants to be called a tourist.

"Traveller" is the preferred appellation, connoting independence, savoir-faire. A traveller may be a loner or an explorer, but a tourist is following a programme. ${ }^{4}$

\footnotetext{
${ }^{3}$ Pela respectiva riqueza.

${ }^{4} \mathrm{O}$ Pequeno Dicionário Oxford de Inglês define o turista como "alguém que viaja por prazer ou cultura, visitando um número de lugares". Mais e mais pessoas são turistas. Turismo é uma das indústrias que mais crescem no mundo industrial moderno e tem mantido este status por mais de vinte anos. Contudo ninguém quer ser chamado de turista.

"Viajante" é a denominação preferida, conotando independência, savoir-faire. Um viajante pode ser um solitário ou um explorador, mas um turista segue uma programação.
} 
O percurso do turista seria, portanto, programado, determinado por guias e por suas próprias limitações financeiras. Os aspectos assumidos por uma viagem habitualmente breve, realizada com recursos predefinidos e associada ao lazer descompromissado seriam ecos da sociedade industrial, caracterizada pela padronização e massificação. Nesse sentido, em descrição de sua experiência como "Turista infeliz", em clara referência à designação do livro de viagens do escritor modernista Mário de Andrade (O turista aprendiz), o escritor e artista plástico Nuno Ramos observa que, contemporaneamente, o estranhamento do contato com a diferença que viajar permitiria é superado pela difusão do mesmo num mundo em que a singularidade cede ao padrão:

As filas, como o lixo, são outra forma contundente do Mesmo. Nelas, o turista lembra que é legião, que tudo está cenografado para ele, que não é o primeiro nem será o último a pisar ali e que muita água rolou entre a autenticidade local, que procura e pela qual pagou, e sua singularíssima pessoa. Seu instante, assim, não pode ser tão mágico, já que hordas o antecederam e o sucederão, e todos os dias o milagre do salto daquele golfinho se repete. (RAMOS, 2013, p. 28)

No entanto, o turismo não se origina como uma prática popular. Para Judith Adler (1998), por exemplo, poder-se-á datar a origem do turismo no século XVI, quando seria realizado pela elite: "Travel was first widely proclaimed as an art, and a openly secular forms of tourism were first systematically practiced by Europeans elites, in the early sixteenth century"5 (ADLER, 1998 , p. 04). Por outro lado, o emprego do termo está associado à busca por prazer no século XIX, expressa no hábito cultivado pela burguesia de passar temporadas em casas de campo ou praia durante o verão, o que vai levar à criação da noção de férias:

Os citadinos que podem viram "turistas". A palavra, sinônimo

${ }^{5}$ A viagem foi primeiro amplamente proclamada como uma arte, enquanto formas abertamente seculares de turismo foram pela primeira vez sistematicamente praticadas pelas elites europeias, no início do século XVI. 
de viajante, data de 1816, mas é Stendhal que realmente consagra seu uso em 1838, com Les mémoires d'un touriste [As memórias de um turista]. O Larrousse du XIXe siècle diz que o turista "viaja por curiosidade e ociosidade". Os turistas não são necessariamente andarilhos ou itinerantes. Podem optar por ficar numa vila junto ao mar, e não arredar mais dali (o termo estivant [veranista] aparece apenas em 1920). (MARTIN-FUGIER, 1991, p.231)

Também Maxine Feifer faz referência a Stendhal como o primeiro a empregar a palavra turismo tal como veio a se consagrar. No entanto, Feifer (1986) propõe um elemento diferencial ao dizer que, embora o termo tenha sido cunhado no século XIX, é possível identificar o turismo desde o antigo Império Romano; pois, segundo ele:

[...] tourists have reappeared periodically ever since (in a continuous and a broadening stream for the last hundred years), variously seeking culture and a pleasure according to the lights of their time. Thus what is sacred in one era becomes a curiosity in another; and latter, it turns into art. ${ }^{6}$ (FEIFER, 1986, p.2)

O historiador apresenta como elemento fundamental do turismo, que teria existido desde a Antiguidade clássica, a capacidade de tornar o comum em exótico. Não é por acaso que o autor abre a introdução do seu livro contando um episódio passado em um hotel na Normandia, onde as pessoas se reuniam para assistir ao preparo de uma omelete famosa por sua consistência e que havia se tornado a especialidade gastronômica da cidade. Diante disto, Feifer (1986, p.1) observa: "The event has become mystified by the curious process that tourism brings into play: set up by the travel writer and a framed by the camera, other people's

${ }^{6}[\ldots]$ turistas têm reaparecido periodicamente desde então (numa corrente contínua e abrangente por centenas de anos), variavelmente em busca de cultura e prazer de acordo com os conhecimentos de sua época. Assim o que é sagrado em uma era se torna uma curiosidade em outra; e mais tarde, torna-se arte. 
ordinary lives are transformed into exotic entertainment, history into myth"'

A transformação do corriqueiro e comum em exótico revela uma estreita ligação entre turismo e exotismo. O que torna a viagem atraente para o turista, entre outras coisas, é a possibilidade de abrir em sua vida comum um espaço de exceção, em que se poderia defrontar com o diferente, que lhe se apresentaria como exotismo. Este, no entanto, pode ser puramente o resultado da valorização de elementos do cotidiano promovida por aqueles que se encarregaram de registrar suas viagens. Desta forma, estarse-ia diante de um processo de fabricação do exotismo, no qual se destacaria o papel desempenhado pelo relato de viagem. Todavia, quem escreve esses relatos? O próprio turista?

Diante da perspectiva de que a viagem inicialmente é uma prática da elite e que apenas após o século XIX se populariza, pode-se afirmar que a possibilidade de viajar, a princípio, não se oferecia democraticamente a qualquer um. Por isso, não foi bem vista pela aristocracia e pela burguesia a criação de condições que permitiram ao homem médio também viajar, na medida em que isto representava perda de uma exclusividade que funcionava também como distinção entre as classes. As modificações decorrentes, dentre outros fatores, da revolução industrial que estimulou a urbanização e gerou novos e melhores meios de transporte, propiciaram a disseminação do hábito de viajar e a consequente necessidade de diferenciação da figura do viajante enquanto parte da elite. Na realidade, o andarilho durante muito tempo foi visto como um aventureiro, alguém que se desprendia pelo mundo submetendo-se a desconfortos e riscos para obter a recompensa de conhecer diferentes culturas e paisagens. A associação entre riqueza e viagem, dada a necessidade de recursos para financiar a jornada do peregrino, não era incomum, embora isto não significasse dizer que apenas a elite viajava. Contudo,

${ }^{7} \mathrm{O}$ episódio foi mistificado pelo processo curioso que o turismo deflagra: instituída pelo escritor de viagens e moldada pela câmera, a vida de pessoas comuns é transformada em entretenimento exótico, e a história, em mito. 
diante da massificação da prática da viagem representada pela indústria do turismo, houve por parte das classes mais altas a necessidade de reafirmação de marcas distintivas como forma de manutenção dos próprios limites sociais: a diferenciação enfática e hierarquizante entre turista e viajante é prova disso.

A valorização da figura do viajante, frente à necessária manutenção do prestígio de uma elite, estaria também relacionada ao saber acumulado por aquele que viajava. A referência ao conhecimento de línguas como um elemento diferenciador entre o turista e o viajante remete à bagagem letrada deste em detrimento daquele. Se, de partida, o viajante se destaca pelo conhecimento que possui das culturas que irá visitar, por outro lado, a oportunidade de viagens mais duradouras the permite a acumulação de conhecimento pelo contato com diferentes povos e paisagens. De fato, a viagem era muitas vezes encarada como parte do processo de formação dos jovens. Seja em pleno século XVI:

Books played a prominent part in the preparation for a journey and their purchase was one of its objects. The aristocratic traveler who was addressed, often by this tutor, in early manuals on advice went abroad for discourse rather than for picturesque views or scenes. ${ }^{8}$ (ADLER, 1998, p.04)

O viajante deveria: "learning foreign tongues, obtaining access to foreign courts, conversing gracefully with eminent men, assimilating classical texts appropriate to particular sites [...]" (ADLER, 1998, p.05).

Ou ainda no século XVIII, quando prevalecia a viagem

\footnotetext{
${ }^{8}$ Livros desempenhavam um importante papel na preparação para a jornada e adquiri-los era um dos objetivos da viagem. O viajante aristocrata que era introduzido, frequentemente por seu tutor, na leitura de antigos manuais ou informativos ia para o estrangeiro pelo discurso mais do que pelas paisagens ou cenas pitorescas.

${ }^{9}$ Aprender línguas estrangeiras, obter acesso a cortes estrangeiras, conversar elegantemente com homens eminentes, assimilar textos clássicos apropriados a lugares particulares [...].
} 
como Grand Tour, na qual se observa igualmente a importância dada ao aspecto pedagógico da jornada:

$[\ldots]$ an increasing number of books appeared arguing in favour of the Grand Tour, and telling how to go about it. It was best, opined the Treatise Concerning the Education of Youth, for the master to travel when he was young and impressionable. Then, he could be more easily dissuaded from rude ways and bad habits, more easily remoulded. [...] The optimum age was about sixteen, just after graduation from university. At that age a chaperon was required [...]. Choosing the right tutor, or governor, was most important. He was the one who would guide the youth towards the refinaments of the Continent $[\ldots]^{10}$ (FEIFER, 1986, p.99).

O domínio do conhecimento decorrente de uma formação esmerada, que compreendia a viagem como uma de suas etapas, daria ao viajante, e tão somente a ele, as condições para a construção de um relato escrito representativo de sua jornada. Assim, o turista não se aventuraria na redação de relatos, tarefa que caberia aos viajantes: "Authors of travel books themselves are often very careful to let readers know they are in the company of a bona fide traveler"11 (RISSE, 1998, p.45).

Diante disso, há considerações que se impõem: prevalece a ideia de que narrar a viagem está em estreita relação com uma condição de elite também intelectual, porque a formação

${ }^{10}[\ldots]$ um número crescente de livros surgiu argumentando a favor do Grand Tour, e dizendo como fazê-lo. Era melhor, opinava o Treatise Concerning the Education of Youth (Tratado sobre a educação do jovem), para o senhor viajar quando fosse jovem e impressionável. Então, ele poderia ser mais facilmente despersuadido dos modos rudes e dos hábitos ruins e mais facilmente remodulado. [...] A idade ótima era dezesseis anos, exatamente após a graduação na universidade. Naquela idade um acompanhante era necessário [...]. Escolher o tutor certo, ou mestre, era o mais importante. Era ele quem guiaria o jovem através dos refinamentos do Continente [...].

11 Os próprios autores de livros de viagem são frequentemente muito cuidadosos em deixar claro para os leitores que estão na companhia de um legítimo viajante. 
privilegiada do viajante permitiria um aproveitamento melhor do aprendizado que the seria oferecido ao longo de suas jornadas e a possibilidade de grandes viagens (em extensão e duração) que lhe dariam a chance de experimentar e acumular conhecimento. Existe, por esse prisma, uma evidente vinculação da atividade intelectual à figura do viajante, em contraposição, é claro, ao turista; daí a delegação da escrita ao primeiro.

É corrente a visão de que o trânsito vai representar um ganho para o viajante, pois lhe permitiria amadurecer por meio das experiências que vivenciaria e do conhecimento que acumularia. A respeito disso, tece comentários Thaïs Cougo Pimentel (1998), em sua Tese de Doutorado - De viagens e de narrativas, a partir do estudo de Eric Leed, segundo o qual, a compreensão da viagem como purgação que prevalecia na Antiguidade vai sobreviver, embora diferenciadamente, na era moderna. Nesta, o sofrimento inerente à jornada participaria de um processo acumulativo de conhecimento e, portanto, do crescimento do indivíduo (PIMENTEL, 1998, p.21). Para o mundo antigo, viajar era uma penitência, uma vez que o sujeito e o seu lugar de origem estavam intensamente integrados. No mundo moderno, viajar passa a ser uma opção e não uma imposição determinada por certas circunstâncias como na Antiguidade: a viagem recebe a marca do voluntarismo.

$\mathrm{O}$ elemento definidor das viagens dos cavaleiros medievais era já ostensivamente voluntário e sem nenhum propósito utilitário; as viagens dos cavaleiros, que são o padrão e o modelo para o significado das viagens modernas, são essencialmente auto-referenciadas, celebradas para revelar o caráter essencial do cavaleiro como 'livre', outrora a essência da nobreza, mas desde o século XVII considerado um atributo da natureza humana. (PIMENTEL, 1998, p. 23)

Tal voluntarismo se relaciona à associação ente viagem e poder. Uma série de questões, portanto, envolve a proposta de classificação que preconiza a distinção entre turistas e viajantes. $\mathrm{O}$ ponto de convergência entre tais questões se situa justamente na 
qualidade de elite que se atribui aos que se intitulam os verdadeiros viajantes, já que o diferencial consiste fundamentalmente em se determinar quem detém o poder (fundado em dois aspectos, na verdade, indissociáveis - o intelectual e o material).

Por outro lado, deve-se atentar para definições de turista, tão abrangentes como a apresentada no livro Tourism in history: from Imperial Rome to the Present (Turismo na História: do Império Romano ao presente), no qual Maxine Feifer coloca em xeque as fronteiras entre os variados tipos de viagem. Sua proposta, na realidade, consiste em fazer uma espécie de reconstituição das práticas dos viajantes de diferentes épocas. Para tanto, o autor recusa a escrita acadêmica, que rege os moldes tradicionais de uma obra de história, e se propõe um texto em que a história se relaciona despretensiosamente com a ficção, ou vice-versa:

Since my aim was to write an entertainment, my method has been to create a prototypical tourist for reach epoch and to follow him on a "typical" tour composed of what reallife tourists did and saw. So each tour is, strictly speaking, a fiction (except the last one, where I speak for myself). (FEIFER, 1986, p.03) ${ }^{12}$

A proposta é valorizar o ficcional com vistas ao entretenimento, o que, no entanto, não significa a negligência de informações históricas, até mesmo porque estas serão vitais para levar adiante a proposta de trabalhar com um protótipo de turista para cada época. Não se trata, por conseguinte, de se estabelecer um parâmetro que possa ser usado como modelo em qualquer momento histórico ou em qualquer civilização: o autor deixa claro tanto os períodos históricos escolhidos quanto o fato de o protótipo ser um britânico.

Todavia, a proposta de construir-se um modelo inclui

${ }^{12}$ Uma vez que o meu desejo era escrever um passatempo, meu método foi criar um protótipo de turista para cada época e acompanhá-lo em um "típico" tour composto a partir daquilo que turistas da vida real fizeram e viram. Então cada tour é, mais precisamente, uma ficção (exceto o último, em que eu falo por mim mesmo). 
necessariamente os aspectos que o autor considera fundamentais para uma caracterização do turista, sem deixar, porém, de se subordinar às peculiaridades históricas. Daí a importância de o historiador ter assinalado, desde o início, que o ponto de vista de que parte é britânico, o que explica ainda protótipos como o turista elizabetano, o grande turista, o vitoriano, até chegar ao que chama de pós-turista. Por outro lado, no processo de construção do modelo do turista, Maxine Feifer (1986) não poupa outras tipificações de viajante, transpondo possíveis barreiras de definição. O desrespeito, por assim dizer, às tipologias se evidencia com maior nitidez quando, por exemplo, no capítulo 2 do livro, o peregrino medieval também é um turista. Isto só é possível graças à acepção de turista que Feifer emprega: aquele que viaja para lugares que lhe são inéditos a fim de divertir-se, contemplar ou adquirir objetos (relíquias, souvenirs,...). O historiador segue, dessa forma, na contramão da compreensão do turismo como um fenômeno essencialmente moderno, ao considerar a sua existência desde o Império Romano.

A formulação de turista tal como a apresenta Feifer permite, de todo modo, problematizar a distinção entre tipos de viajantes, pois considera a existência destes sem, no entanto, admitir que entre eles se construam fronteiras rígidas e intransponíveis. De qualquer maneira, o ponto de vista do autor certamente é apenas um dentre muitos assim como a classificação com que trabalha não é a única entre aqueles que se preocupam em refletir sobre a viagem ao longo da história.

Quando se trata de uma tipologia que considera a dicotomia entre viajantes que efetivamente se lançariam em jornadas e os que vivenciam a viagem apenas na imaginação, está-se propondo, claramente, uma divisão rígida entre real e imaginário. Em vez de se pensar em termos de dois tipos bem determinados de viajantes, talvez fosse mais interessante distanciar-se da distinção pretensamente perfeita e estanque entre grupos de viajantes segundo critérios fundados em quão reais ou imaginárias seriam suas viagens, para se concentrar precisamente na tensa zona de 
interseção entre realidade e fantasia, em que uma e outra circulam indistintamente. A independência dos tipos seria, portanto, corroída pela existência de uma região tensa e sensível em que se inscreveria a problemática diferenciação entre ficcional e nãoficcional.

O elemento subversivo que impede a formação de dois tipos tão bem definidos é justamente a imaginação que orienta a pena do narrar. A escrita se oferece como espaço de circulação para o imaginário mesmo quando o que se pretende é o relato fidedigno de uma viagem que de fato teria ocorrido. Na verdade, os que realizam percursos também o fazem por caminhos de tinta e papel, daí ser necessário pensar não em dois grupos distintos, mas em interseção - a escrita enquanto espaço de fronteiras esgarçadas e porosas, ponto de contato que torna questionável a própria divisão construída a partir do real e do imaginário. Assim, se o ponto de partida, a perspectiva escolhida para leitura da viagem, é a própria escrita, não se justifica um estudo preocupado unicamente com a avaliação de um determinado gênero, no caso, a literatura de viagem, ou mesmo voltado para definição de certo texto como relato fiel. A fenda do imaginário aberta pela escrita ganha posição de destaque na leitura crítica que se propõe. De fato, a viagem não é aqui entendida como exclusivamente real ou imaginária, porque se confundem aquela que se operou na realidade e a que se desenhou pela escrita. Abandona-se a busca por relatos de viagem enquanto gênero e abre-se espaço para a poesia e a ficção.

\section{Considerações finais}

A discussão acerca das relações entre viagem e escrita assim como dos possíveis tipos de viajantes leva à enriquecedora problematização de aspectos por vezes negligenciados. Assim, diante das classificações discutidas, num primeiro momento, pode-se observar a existência de uma posição acentuadamente hierarquizante ao se contrapor o viajante ao turista. Viajar de 
verdade seria, por esse viés, prerrogativa de uma elite apta a isso e a viagem estaria intimamente associada a um processo de formação, pois representaria antes de mais nada a possibilidade de crescimento intelectual e mesmo moral. Todavia, é também destinada ao viajante a tarefa da escrita, pois somente a ele são atribuídas as condições intelectuais que permitiriam o registro da viagem. Isso caracteriza, obviamente, tal viajante como elite também intelectual. Nesse sentido, a escrita seria encarada também como marca distintiva capaz de identificar o verdadeiro viajante.

Por outro lado, a preocupação em dividir viagens reais e imaginárias pode ser, por seu caráter dicotômico, extremamente empobrecedora, quando não se leva em conta o quão frustrante pode ser a pretensão de se identificarem limites precisos entre uma e outra. Afinal, ao se percorrer caminhos de tinta e papel para relatar uma viagem realizada, não se está imune à imaginação. Se, porém, o ponto de vista escolhido para a leitura do texto do viajante se assenta no espaço concedido à imaginação, a diferenciação absoluta entre a viagem feita no papel e a que se desenha nas estradas perde o sentido. Desse modo, abre-se mão de uma visão polarizada e taxionômica a favor de uma perspectiva fundada na relação de mão dupla que se pode observar entre viagem e escrita, já que, no momento em que aquela se inscreve nesta, viajar e escrever tornam-se praticamente indissociáveis.

\section{REFERÊNCIAS}

ADLER, Judith. Origins of sightseeing. In: WILLIAMS, Carol Traynor, (Ed). Travel Culture: essays on what makes us go. Westport; Connecticut; London: Praeger, 1998. p. 03-24

BADIKIAN, Beatriz. Mapmaking: the Poet as a Travel Writer. In: WILLIAMS, Carol Traynor, (Ed.). Travel Culture: essays on what makes us go. Westport; Connecticut; London: Praeger, 1998. p. 73-78

BENJAMIN, Walter. Obras escolhidas: Magia e técnica, arte e política. Tradução Sérgio Paulo Rouanet. São Paulo: Brasiliense, 1994. 
CALVINO, Italo. As cidades invisíveis. Tradução Diogo Mainardi. São Paulo: Companhia das Letras, 1994.

FEIFER, Maxine. Tourism in history: from Imperial Rome to the present. New York: Stein and Day, 1986.

GIUCCI, Guillermo. Viajantes do maravilhoso. Tradução Cristina Cavalcanti. Rio de Janeiro: Centro Interdisciplinar de Estudos Contemporâneos, 1989.

GOMES, Renato Cordeiro. Todas as cidades, a cidade: literatura e experiência urbana. Rio de Janeiro: Rocco, 1994.

KAPLAN, Caren. Questions of travel: Postmodern discourses of displacement. Durhan and London: Duke University Press, 1996.

LÉVI-STRAUSS, Claude. Tristes Trópicos. Tradução Rosa Freire d'Aguiar. São Paulo: Companhia das Letras, 1996.

MARTIN-FUGIER, Anne. Os ritos da vida privada burguesa. In: PERROT, Michelle et al. História da vida privada, 4: da Revolução Francesa à Primeira Guerra. São Paulo: Companhia das Letras, 1991. p. 193-262.

MUSARRA, Ulla. Narrative discourse in postmodernist texts. In: CALINESCU, Douwe. Exploring postmodernism. Amsterdam; Philadelphia: J. Benjamins, 1990.

PIMENTEL, Thais Velloso Cougo. De viajantes e de narrativas: viajantes brasileiros no além-mar. (1913-1957). - Tese de Doutorado em História Social - Faculdade de Filosofia, Letras e Ciências Humanas, USP, São Paulo, 1998.

POLO, Marco. O livro das maravilhas. Tradução Elói Braga Júnior. Porto Alegre: L\&PM, 1999.

RAMOS, Nuno. O turista infeliz. Piauí, n. 78, p.26-29, mar. 2013.

RISSE, Marielle. White knee socks versus photojournalist vests: distinguishing between travelers and tourists. In: WILLIAMS, Carol Traynor, (Ed.). Travel Culture: essays on what makes us go. Westport; Connecticut; London: Praeger, 1998. p. 40-50 
SANTIAGO, Silviano. Nas malhas da letra. São Paulo: Companhia das Letras, 1989.

SOUTO, Elvira. Viagens na literatura. Santiago de Compostela: Laiovento, 1991.

YOSELOFF, Thomas. Introduction. In: POLO, Marco. The travels of Marco Polo. New York: Fine Editions Press, 1956.

Recebido em 31/03/2013.

Aprovado em 17/10/2013. 